\title{
Translation, cultural adaptation, and evaluation of the psychometric properties of an Arabic diabetes distress scale
}

\author{
A cross sectional study from Saudi Arabia
}

Mohammed A. Batais, MBBS, SBFM, Fahad D. Alosaimi, MD, Abdulrahman A. AlYahya, Medical Intern, Ouf A. Aloofi, Medical Intern, Mohammad K. Almashouq, Medical Intern, Khalid S. Alshehri, Medical Intern, Abdulaziz F. Alfraiji, Medical Intern.

\begin{abstract}
الأهداف: ترجمة مقياس ضائقة داء السكري ذو السبعة عشر عنصرًا

(DDS-17)

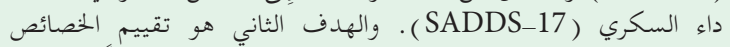

السيكومترية للمقياس السعودي لضائقة داء السكري المعدل حلـ حديثًا.

المنهجية: هذه دراسة مستعرضة لتقييم الخصائص السيكومترية لمقياس

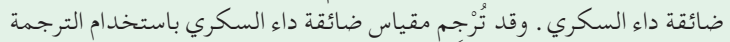

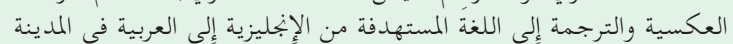

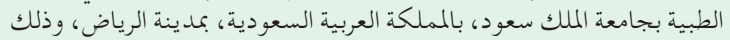

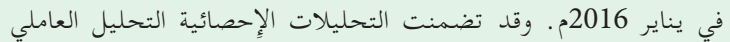

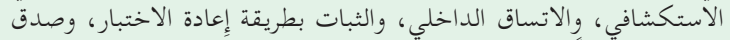

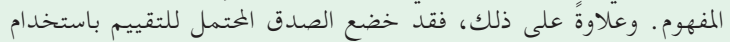

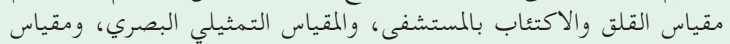

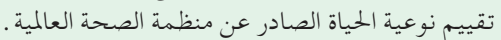

النتائج : يتكون مجتمع الدراسة من 109 مشاركًا. و وقد دَعْمِ التحليلُ العاملي

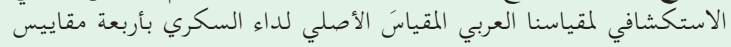

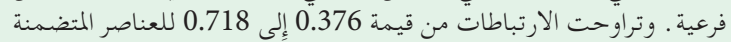

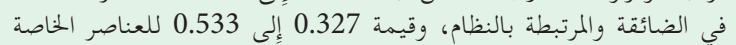

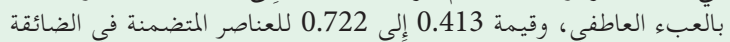

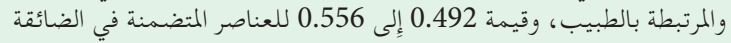

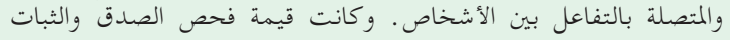

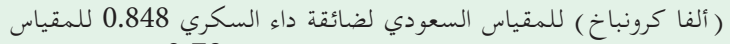

الإجمالي ـ وكانت قيمة الثبات بطريقة إعادة الاختبار 0.78.

الحلاصة : المقياس السعودي لضائقة داء السكري في المملكة العربية السعودية

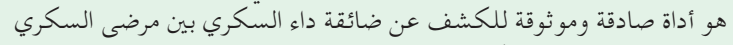

من النوع الثاني في المملكة العربية السعودية .
\end{abstract}

Objectives: To translate, validate, and adapt the diabetes distress scale (DDS)-17 to a Saudi Arabian (SA) DDS (SADDS-17). Also, to evaluate the psychometric properties of the newly adapted SADDS-17.

Methods: This was a cross-sectional study evaluating the psychometric properties of the DDS. The DDS was translated using the forward-backward translation from English to Arabic at King Saud University Medical City (KSUMC), Riyadh, Saudi Arabia, in January 2016. Statistical analyses included exploratory factor analysis, internal consistency, testretest reliability, and construct validity. Moreover, contingent validity was evaluated using hospital anxiety and depression scale, visual analogue scale, and the World Health Organization quality of life assessment instrument.

Results: A total of 109 participants were included in this study. The exploratory factor analysis of our Arabic scale supported the original DDS with 4 sub-scales. Correlations ranged from 0.376 to 0.718 for items in regimen-related distress, 0.327 to 0.533 for items in emotional burden, 0.413 to 0.722 for items in physician-related distress, and 0.492 to 0.556 for items in interpersonal distress. The Cronbach's alpha value of the SADDS was 0.848 for the total scale. The test-retest reliability value was 0.78 .

Conclusion: Our SADDS is a valid and reliable instrument for detecting diabetes distress among Saudi Arabian patients with type 2 diabetes.

Keywords: diabetes distress, diabetes mellitus, Arabic, Riyadh, Saudi Arabia, validity

Saudi Med J 2021; Vol. 42 (5): 509-516 doi: 10.15537/smj.2021.42.5.20200286

From the Department of Family and Community Medicine (Batais); From the Department of Psychiatry (Alosaimi); and from the College of Medicine (AlYahya, Aloofi, Almashouq, Alshehri, Alfraiji), King Saud University Medical City, King Saud University, Riyadh, Kingdom of Saudi Arabia.

Received 6th March 2021. Accepted 22nd March 2021.

Address correspondence and reprint request to: $D r$. Abdulaziz $F$. Alfraiji, King Saud University Medical City, King Saud University, Riyadh, Kingdom of Saudi Arabia. E-mail: Azizalfraiji@gmail.com ORCID ID: https://orcid.org/0000-0002-5405-5045 
$\mathrm{D}$ iabetes mellitus (DM) is a growing burden, both in Saudi Arabia and internationally. According to the latest data from the International Diabetes Federation (IDF), it is estimated that 463 million people have DM. The IDF estimated that, by 2045 , DM would affect 700 million people. ${ }^{1}$ In Saudi Arabia, type 2 DM presents a major morbidity burden, with a prevalence ranging from $18.2 \%$ to $31.6 \%$ in the $7-80$ years old age group. ${ }^{2}$ The prevalence of diabetes distress in Saudi Arabia has been estimated in only 2 cities: Taif (25\%)and Jazan $(22.3 \%))^{3,4}$

Managing the chronic disorder of DM, together with its disabling complications, can make patients prone to depressive symptoms, as seen by the higher prevalence of depression in people with type 2 diabetes compared with the general population. ${ }^{5}$ Mental illnesses, such as depression and anxiety, share similar aspects with diabetes distress. Thus, discrimination between each entity can be difficult. ${ }^{6}$ Diabetes distress is defined as a hidden emotional condition caused by worries, fears, and frustrations from living with a progressively disabling illness, such as diabetes, and its management. ${ }^{7}$ Fisher et $\mathrm{al},{ }^{6}$ have mentioned that those with diabetes who exhibit depressive affect might not be suffering from clinical depression, rather the continuous worrying on this chronic illness and its management can lead to an enormous level of emotional distress. ${ }^{8}$ Moreover, diabetes distress has shown to be related to the glycemic control when compared to depression. ${ }^{7}$ Thus, the use of validated screening tools, such as the diabetes distress scale (DDS-17), for assessment of diabetes-related emotional distress has gained growing significance in recent years. ${ }^{?}$

Arab countries cover a large geographical area and express moderate cultural differences; we have found two studies that have validated an Arabic version of the DDS-17, one of which was in Jordan ${ }^{10}$ and the other was in Taif city. ${ }^{11}$ The population of the aforementioned studies included age 18 or older, type $2 \mathrm{DM}$ in both, while the Jordanian included any DM provided that it was diagnosed for more than a year. Taif study has excluded cancer, untreated hyperthyroidism, gestational diabetes, and psychiatric illness. Furthermore, the Jordanian study has excluded patients with severe physical, mental or cognitive deterioration. Both studies displayed cultural and methodological variations that

Disclosure. Authors have no conflict of interests, and the work was not supported or funded by any drug company. led to different factor loading in the aforementioned studies. To fulfill the cultural variation gap, a previous study had recommended the re-validation and translation of an Arabic DDS-17. ${ }^{11}$ Therefore, our study aimed to translate, validate and adapt the DDS-17 to a Saudi Arabian DDS (SADDS-17). The second aim was to evaluate the psychometric properties of the newly adapted SADDS-17.

Methods. This was a cross-sectional study evaluating the psychometric properties of SADDS-17. This study targeted Saudi adults with type 2 DM; moreover, the accessible population included patients with type 2 DM attending diabetes clinics of King Saud University Medical City (KSUMC), Riyadh, Saudi Arabia. Participants were adults with type 2 DM (age $>18$ years) who were fluent in Arabic. They were recruited between January 2016 and April 2017. People with type $1 \mathrm{DM}$ and those with severe DM complications or severe mental illnesses, such as active psychosis or dementia were excluded based on the literature. ${ }^{11,12}$ The sample size was 177 participants, with 68 excluded due to missing data. This exclusion was carried out to ensure the validity and reliability of the assessed scale by including only complete responses and does not reflect unclarity of the items in the questionnaire. Many of the participants (73\%) had low education and due to the cultural constraints, it was challenging to receive complete information from female participants. Previous studies on the subject topic have used even lesser number of subjects and as such a smaller sample size does not reflect any significant shortcomings. ${ }^{13}$

After receiving permission from the providers of the original DDS- $17,{ }^{14}$ it was translated following the guidelines of Beaton et al. ${ }^{15}$ Beginning with the translation of the original English version to an Arabic version by 2 bilingual native Arabic speakers, one of which had medical expertise and knew the goal of the study, but the other did not. Then, 2 bilingual native English speakers back-translated the Arabic version into an English version to ensure the validity of each item in the translated version to the original version. A committee of experts was formed comprising 2 psychiatrists, 2 family medicine physicians, and an epidemiologist. This committee aimed to finalize the Arabic version of DDS-17 by cultural adaptation to the Saudi culture. The Arabic version was tested on 30 participants and their opinions were considered to maintain the quality of adaptation. We have taken into consideration the advises provided by such participants in regard to the font size and method of answering. 
However, no changes were made to the content of the questionnaire.

Participants were included via a systematic random sampling technique, by including every third patient from the diabetes clinics' appointment list of KSUMC. After providing written informed consent, participants were interviewed (face-to-face questionnaire) by trained data collectors.

This study was approved by the Institutional Review Board (IRB) at the College of Medicine, King Saud University, Riyadh, Saudi Arabia. Moreover, contingent validity was evaluated using hospital anxiety and depression scale, visual analogue scale and World Health Organization quality of life assessment instrument.

The DDS-17 consists of 17 items describing possible diabetes-related problems. ${ }^{14}$ Each item is scored from 1 (no distress) to 6 (serious distress) concerning distress experienced over the last month. Scoring of this scale involves the summation of participant's responses to the appropriate items and dividing the total score by the number of items in the corresponding scale. Participants were categorized into 2 diabetes distress groups: low $(<3)$ and high $(\geq 3) .{ }^{16}$ The DDS-17 has 4 domains of diabetes-related distress (DRD): emotional burden (EB), physician-related distress (PD), regimenrelated distress $(\mathrm{RD})$, and diabetes-related interpersonal distress (ID).

The hospital anxiety and depression scale (HADS) consists of 14 items; this scale was used to determine the level of anxiety and depression. Each item has 4 responses that describe the range of severity. Scoring of HADS was calculated by comparing the subject's total summed points to the evaluation scales, where the total score of 0-7 was considered within the normal range, 8-10 considered within the borderline abnormal range, and a score of 11-21 in the abnormal range. Prior permission to use a translated and validated Arabic version of this scale was obtained. ${ }^{17}$

The visual analogue scale (VAS) is a visual scale that allows participants to evaluate themselves in terms of compliance with the doctor's management instructions. ${ }^{18}$ The participant views a horizontal line that contains 11 small vertical lines with each vertical line numbered sequentially from 0 to 10 , with 0 representing not compliant at all and ten meaning fully compliant. Participants who had a score of 8 or above were considered as adherent to the doctor's instructions towards medication, whereas under 8 represents the non-adherent group. This aforementioned classification has been used in published studies among various medical populations. ${ }^{19}$
The World Health Organization quality of life assessment instrument, short version (WHOQOLBREF). This scale contains 26 items that target the past two weeks of a participant's life to evaluate their quality of life. There are 4 domains to which quality of life scale assesses: physical health domain, psychological domain, social relationships domain, and environment domain. Answers of this scale are ranged from one to five for each item. The total score ranges from 25 to 100; higher scores indicate a higher quality of life. ${ }^{20}$ Prior permission to use a validated Arabic version of this scale was obtained. ${ }^{21}$

Statistical analysis. The data were analyzed using Statistical Package for Social Sciences, version 21 (IBM Corp., New York, NY, USA). The Pearson correlation 2-tailed test ( $p=0.01, p=0.5$ ) was used for the correlation between SADDS-17 scores and the other variables for test-retest reliability and Cronbach's alpha was used to test internal consistency. Exploratory factor analysis (EFA) was used to identify the underlying structure of the variables which also yielded correlations among items of the SADDS-17. Principal axis factoring and oblique promax rotation in factor analysis were used to test the construct validity of the SADDS-17 (factor loading). Correspondence analysis was used for the dimensionality assessment of the SADDS-17. Cronbach's alpha was used to test the internal consistency reliability of the SADDS-17. A 3-week interval was for the test re-test reliability of the SADDS-17, the sample size consisted of 20 subjects.

Results. A total of 109 participants were included in data analysis, of which the majority were females $(60.6 \%)$, married $(70.6 \%)$, had a family income less than SAR $15000(75.2 \%)$, and had less than a high school education (73.4\%). The mean participants' age was $56.94 \pm 9.78$ years. Further demographic details of the study participants are provided in Table 1.

Participants reported a relatively high level of DRD of $48.94 \%$ (mean score of $41.6 \pm 15.24$ out of a possible $85)$. The highest contributor of DRD was EB, yielding $55.56 \%$ (mean score of $13.89 \pm 6.43$ out of a possible $25)$. The next highest contributor was RD $50.35 \%$ (mean score of $12.59 \pm 6.29$ out of a possible 25), followed by PD $45.37 \%$ (mean score of $9.07 \pm 5.56$ out of a possible 20), and ID $40.31 \%$ (mean score 6.05 $\pm 3.88)$.

Correlation of SADDS-17 scores with participants' demographics and psychological parameters. The results displaying correlations between the participants' SADDS-17 scores and the participants' demographics and psychological parameters have been displayed 
Table 1 - Demographic variables frequency.

\begin{tabular}{|c|c|}
\hline Variables & n (\%) \\
\hline \multicolumn{2}{|l|}{ Gender } \\
\hline Male & $43(39.4)$ \\
\hline Female & $66(60.6)$ \\
\hline \multicolumn{2}{|l|}{ Social status } \\
\hline Single & $5(4.6)$ \\
\hline Married & $77(70.6)$ \\
\hline Widow & $20(18.3)$ \\
\hline Divorced & $7(6.4)$ \\
\hline \multicolumn{2}{|l|}{ Education level } \\
\hline Illiterate & $21(19.3)$ \\
\hline Elementary & $15(13.8)$ \\
\hline Secondary & $13(11.9)$ \\
\hline High school & $31(28.4)$ \\
\hline Bachelor & $21(19.3)$ \\
\hline Postgraduate & $8(7.3)$ \\
\hline \multicolumn{2}{|l|}{ Occupation } \\
\hline Unemployed & $53(48.6)$ \\
\hline Governmental sector employee & $22(20.2)$ \\
\hline Businessman & $4(3.7)$ \\
\hline Retired & $4(3.7)$ \\
\hline Private sector employee & $26(23.9)$ \\
\hline \multicolumn{2}{|l|}{ Smoking } \\
\hline Non-smoker & $81(74.3)$ \\
\hline Smoker & $28(25.7)$ \\
\hline \multicolumn{2}{|l|}{ Age } \\
\hline$<40$ & $4(3.7)$ \\
\hline 40 to 59 & $61(56)$ \\
\hline$>60$ & $44(40.3)$ \\
\hline \multicolumn{2}{|l|}{ Family income, Saudi Riyals } \\
\hline$<5000$ & $34(31.2)$ \\
\hline $5000-10000$ & $28(25.7)$ \\
\hline $10000-15000$ & $20(18.3)$ \\
\hline $15000-20000$ & $12(11)$ \\
\hline$>20000$ & $15(13.8)$ \\
\hline \multicolumn{2}{|l|}{ Duration of diabetes } \\
\hline$<10$ & $51(46.8)$ \\
\hline 10- 19 & $36(33)$ \\
\hline $20-29$ & $16(14.7)$ \\
\hline$>30$ & $6(5.5)$ \\
\hline
\end{tabular}

in Table 2. Smoking and VAS scores for medication adherence had a significant negative correlation with the total SADDS-17 scores at $\mathrm{r}=-0.195 \quad(p=0.05)$ and $\mathrm{r}=-0.263(p=0.05)$, respectively. However, total SADDS-17 scores did not correlate with age or duration of diabetes, gender, social status, occupation, educational level, family income, number of family members under care, use of cigarettes, hookah, or antidepressant medication.

In regard to convergent validity of the SADDS-17, the results show a significant positive correlation between total SADDS-17 and HADS depression scores $(\mathrm{r}=0.392, p=0.01)$. In addition, the EB domain was found to have a significant positive correlation with the total scores of depression in HADS score $(r=0.420$, $p=0.01$ ). Furthermore, the total SADDS-17 scores had a positive correlation with the HADS anxiety scores $(\mathrm{r}=0.407, p=0.01)$, whereas the $\mathrm{r}$-values of the $\mathrm{EB}$ was $0.442(p=0.01)$ and PD subscale was $0.249(p=0.01)$. Moreover, the total SADDS-17 had significant negative correlations with the quality of life Environment domain score (WHOQOL-BREF) ( $\mathrm{r}=-0.238, p=0.01)$. Validity and factor analysis of SADDS-17. The ability to perform factor analysis, in terms of sufficient correlation between items of the SADDS-17, using Kaiser-Meyer-Oklin measure of sampling adequacy was found to be middling with a value of 0.74 and consistent with Bartlett's test of sphericity (approximate Chi-square $=879.5, p<0.001) .{ }^{22}$

The results of the factor analysis revealed a 4 -factor solution to the data that was supported by the scree plot, with an eigenvalue of 9.72 and an explained variance of $64.81 \%$. All items of the SADDS-17 were retained in the factor analysis, as all had a factor loading $>0.40$ (Table 3), without any cross-loaded items. The order of distribution of items was: 5 items were clustered in $\mathrm{RD}$ (factor 1), 5 items in EB (factor 2), 4 items in physician related distress (factor 3 ), and 3 items in interpersonal distress (factor 4). The item that had the highest loading (0.875) was item 12 , "Feeling that my doctor doesn't give me clear enough directions on how to manage my diabetes", whereas the lowest loading (0.597) was item 5 , "Not feeling motivated to keep up my diabetes selfmanagement".

Saudi Arabian DDS-17 inter-correlation. Table 4 shows the inter-item correlations for the 17 items on the SADDS-17. Correlations ranged from 0.376 to 0.718 for items in RD (factor 1), 0.327 to 0.533 for items in $\mathrm{EB}$ (factor 2), 0.413 to 0.722 for items in PD (factor 3 ), and 0.492 to 0.556 for items in ID (factor 4). Minimal high interactions (such as, correlations above 0.70 ) were noted with just 2 incidents distributed in 2 factors, which indicate minimal possible item redundancy. It was also noted that RD (factor 1) and PD distress (factor 3) had the highest inter-item correlations.

Reliability. To assess the internal consistency of the SADDS-17, Cronbach alpha was used for the total scale and subscales. Results revealed a Cronbach alpha value of 0.848 for the total scale, whereas it ranged between 0.789 (interpersonal distress) and 0.854 (regimenrelated) for the subscales, indicating a high internal consistency for the SADDS-17. 
Table 2 - Correlation of SADDS-17 scores with participants' demographics and psychological predictors.

\begin{tabular}{|c|c|c|c|c|c|}
\hline Variables & $\begin{array}{l}\text { Total } \\
\text { score }\end{array}$ & $\begin{array}{l}\text { Factor } 1 \text { (regimen } \\
\text {-related distress) }\end{array}$ & $\begin{array}{c}\text { Factor } 2 \\
\text { (emotional burden) }\end{array}$ & $\begin{array}{l}\text { Factor } 3 \text { (physician- } \\
\text { related distress) }\end{array}$ & $\begin{array}{c}\text { Factor } 4 \text { (interpersonal } \\
\text { distress) }\end{array}$ \\
\hline Gender & 0.08 & -0.151 & 0.154 & 0.134 & -0.018 \\
\hline Age & 0.031 & -0.056 & -0.029 & 0.036 & 0.104 \\
\hline Social status & 0.118 & -0.16 & $0.201^{*}$ & 0.119 & 0.08 \\
\hline Educational level & -0.184 & -0.002 & -0.115 & -0.133 & -0.107 \\
\hline Occupation & -0.153 & 0.059 & $-0.254^{\dagger}$ & 0.008 & -0.073 \\
\hline Family income & -0.096 & 0.13 & -0.187 & -0.01 & -0.128 \\
\hline Duration of diabetes & 0.086 & 0.128 & 0.117 & -0.097 & -0.021 \\
\hline Number of family members under your care & -0.114 & 0.054 & -0.128 & -0.042 & -0.163 \\
\hline Smoking & $-.195^{*}$ & -0.146 & -0.081 & -0.101 & -0.007 \\
\hline Cigarettes & 0.162 & 0.067 & 0.008 & 0.16 & 0.101 \\
\hline Hookah & -0.015 & -0.108 & -0.028 & 0.101 & 0.026 \\
\hline Anti-depressant medication & -0.138 & 0.04 & $-.210^{*}$ & -0.007 & -0.115 \\
\hline $\begin{array}{l}\text { Visual analogue scale for medication } \\
\text { adherence }\end{array}$ & $-0.263^{\dagger}$ & $-0.317^{\dagger}$ & -0.1 & -0.087 & 0.02 \\
\hline Quality of life physical health domain & -0.146 & -0.043 & -0.109 & 0.01 & -0.183 \\
\hline Quality of life psychological domain & -0.114 & -0.151 & -0.02 & 0.038 & -0.15 \\
\hline Quality of life social relations domain & $-0.238^{*}$ & -0.09 & -0.158 & 0.025 & $-0.321^{\dagger}$ \\
\hline Quality of life environment domain & $-0.270^{\dagger}$ & -0.083 & -0.115 & -0.087 & $-0.333^{\dagger}$ \\
\hline HADS - anxiety & $0.407^{\dagger}$ & -0.004 & $0.442^{\dagger}$ & $0.249^{\dagger}$ & 0.117 \\
\hline HADS - depression & $0.392^{\dagger}$ & 0.091 & $0.420^{\dagger}$ & 0.153 & 0.102 \\
\hline
\end{tabular}

${ }^{*}$ Correlation is significant at the 0.05 level (2-tailed). ${ }^{\dagger}$ Correlation is significant at the 0.01 level (2-tailed).

HADS: hospital anxiety and depression scale

The dimensionality of the SADDS-17 was assessed using corrected item-total correlation (such as, excluding the item itself in the total scale score), which gave a value of 0.44 . The mean inter-item correlation was 0.53 (range $=0.22$ to 0.79 ).

The test-retest reliability coefficient of SADDS-17 was 0.78 , which is above the acceptable cut-off value of 0.7 .

Discussion. This study shows that this culturally adapted Arabic version of the DDS-17 has reliability and validity in people with type 2 DM in Saudi Arabia. The construct validity of the SADDS-17 used in this study revealed a 4 -factor model that explained $64.81 \%$ of the variance with a factor loading greater than 0.40 with no cross-loading in items. The SADDS-17 was similar to the original questionnaire reported by Polonsky et $\mathrm{al},{ }^{14}$ which revealed no cross-loaded items and a 4-factor distribution, except for the order, as 5 items were clustered in RD (factor 1), 5 items in EB (factor 2), 4 items in PD (factor 3), and 3 items in ID (factor 4).

Our findings are in line with what was reported by an Arabic speaking country (Jordan), which shares a good amount of our culture. ${ }^{11}$ This contrasts what was reported in China, ${ }^{23}$ which showed a 3 -factor model with double loading of both Item 12 ("not sticking closely enough to a good meal plan”) and item 15 ("not having a doctor who I can regularly see about my diabetes"). Another study carried out in $\mathrm{Malay}^{24}$ also revealed a 3-factor model with different allocations of Item 3 ("not feeling confident in my day-to-day ability to manage diabetes"), item 7 ("feeling that I will end up with serious long-term complications, no matter what I do"), and item 15 ("feeling that I don't have a doctor who I can see regularly enough about my diabetes") between the subscales. This discrepancy is perhaps explained by language and cultural variations between different communities.

The internal consistency of the SADDS-17 using Cronbach's alpha was 0.848 for the total scale and 0.789 to 0.854 for the 4 subscales, which has achieved the acceptable cut-off point of 0.70 . These were consistent with the internal consistency results reported in the original DDS-17, ${ }^{14}$ which was 0.87 . Our findings are also in line with other translated versions, including Norwegian, ${ }^{25}$ Chinese, ${ }^{23}$ and Persian. ${ }^{26}$

The SADDS-17 total scale and subscales revealed a significant positive correlation with participants' depressive symptoms elicited in HADS depression scores, which provides evidence of the instrument's validity. Previous studies have also shown a significant 
Table 3 - Factor analysis of SADDS-17 scale with item-loading on each factor.

\begin{tabular}{|c|c|c|c|c|c|c|}
\hline Item & Statement & $\begin{array}{c}\text { SADDS } \\
\text { Dimensions }(\alpha)\end{array}$ & $\begin{array}{l}\text { Factor 1 } \\
\text { (regimen - } \\
\text { related distress) }\end{array}$ & $\begin{array}{l}\text { Factor } 2 \\
\text { (emotional } \\
\text { burden) }\end{array}$ & $\begin{array}{l}\text { Factor } 3 \\
\text { (physician } \\
\text {-related distress) }\end{array}$ & $\begin{array}{c}\text { Factor } 4 \\
\text { (interpersonal } \\
\text { distress) }\end{array}$ \\
\hline 1 & $\begin{array}{l}\text { Feeling that I am not testing my blood sugars frequently } \\
\text { enough. }\end{array}$ & $\begin{array}{l}\text { Regimen } \\
\text { distress }\end{array}$ & 0.743 & & & \\
\hline 2 & Feeling that I am often failing with my diabetes regimen. & & 0.838 & & & \\
\hline 3 & $\begin{array}{l}\text { Not feeling confident in my day-to-day ability to manage } \\
\text { diabetes. }\end{array}$ & & 0.841 & & & \\
\hline 4 & $\begin{array}{l}\text { Feeling that I am not sticking closely enough to a good meal } \\
\text { plan. }\end{array}$ & & 0.828 & & & \\
\hline 5 & $\begin{array}{l}\text { Not feeling motivated to keep up my diabetes self- } \\
\text { management. }\end{array}$ & & 0.597 & & & \\
\hline 6 & $\begin{array}{l}\text { Feeling that diabetes is taking up too much of my mental } \\
\text { and physical energy every day. }\end{array}$ & $\begin{array}{l}\text { Emotional } \\
\text { burden }\end{array}$ & & 0.683 & & \\
\hline 7 & $\begin{array}{l}\text { Feeling angry, scared, or depressed when I think about } \\
\text { living with diabetes. }\end{array}$ & & & 0.716 & & \\
\hline 8 & Feeling that diabetes controls my life. & & & 0.733 & & \\
\hline 9 & $\begin{array}{l}\text { Feeling that I will end up with serious long-term } \\
\text { complications, no matter what I do. }\end{array}$ & & & 0.785 & & \\
\hline 10 & $\begin{array}{l}\text { Feeling overwhelmed by the demands of living with } \\
\text { diabetes. }\end{array}$ & & & 0.602 & & \\
\hline 11 & $\begin{array}{l}\text { Feeling that my doctor doesn't know enough about diabetes } \\
\text { and diabetes care. }\end{array}$ & $\begin{array}{l}\text { Physician- } \\
\text { related distress }\end{array}$ & & & 0.864 & \\
\hline 12 & $\begin{array}{l}\text { Feeling that my doctor doesn't give me clear enough } \\
\text { directions on how to manage my diabetes. }\end{array}$ & & & & 0.875 & \\
\hline 13 & $\begin{array}{l}\text { Feeling that my doctor doesn't take my concerns seriously } \\
\text { enough. }\end{array}$ & & & & 0.713 & \\
\hline 14 & $\begin{array}{l}\text { Feeling that I don't have a doctor who I can see regularly } \\
\text { about my diabetes. }\end{array}$ & & & & 0.664 & \\
\hline 15 & $\begin{array}{l}\text { Feeling that friends or family are not supportive enough of } \\
\text { my self-care efforts (such, planning activities that conflict } \\
\text { with my schedule, encouraging me to eat the "wrong" food). }\end{array}$ & $\begin{array}{l}\text { Interpersonal } \\
\text { distress }\end{array}$ & & & & 0.81 \\
\hline 16 & $\begin{array}{l}\text { Feeling that friends or family don't appreciate how difficult } \\
\text { living with diabetes can be. }\end{array}$ & & & & & 0.85 \\
\hline 17 & $\begin{array}{l}\text { Feeling that friends or family don't give me the emotional } \\
\text { support that I would like. }\end{array}$ & & & & & 0.8 \\
\hline
\end{tabular}

SADDS-17: Saudi Arabian diabetes distress scale-17

Table 4 - Saudi Arabian diabetes distress scale-17 (SADDS-17) inter-item correlation matrix.

\begin{tabular}{lccccccccc}
\hline SADDS & SADDS & SADDS & SADDS & SADDS & SADDS & SADDS & SADDS & SADDS & SADDS \\
Items & $\mathbf{1}$ & $\mathbf{2}$ & $\mathbf{3}$ & $\mathbf{4}$ & $\mathbf{5}$ & $\mathbf{6}$ & $\mathbf{7}$ & $\mathbf{8}$ & $\mathbf{9}$ \\
\hline SADDS 1 & 1 & 0.029 & 0.327 & 0.084 & 0.114 & 0.121 & -0.004 & 0.471 & 0.154 \\
SADDS 2 & 0.029 & 1 & 0.075 & 0.722 & -0.03 & 0.149 & 0.262 & 0.135 & 0.564 \\
SADDS 3 & 0.327 & 0.075 & 1 & 0.091 & 0.288 & 0.144 & 0.106 & 0.364 & 0.183 \\
SADDS 4 & 0.084 & 0.722 & 0.091 & 1 & 0.091 & 0.232 & 0.033 & 0.093 & 0.459 \\
SADDS 5 & 0.114 & -0.03 & 0.288 & 0.091 & 1 & 0.453 & 0.042 & 0.108 & 0.104 \\
SADDS 6 & 0.121 & 0.149 & 0.144 & 0.232 & 0.453 & 1 & 0.16 & 0.115 & 0.212 \\
SADDS 7 & -0.004 & 0.262 & 0.106 & 0.033 & 0.042 & 0.16 & 1 & 0.146 & 0.158 \\
SADDS 8 & 0.471 & 0.135 & 0.364 & 0.093 & 0.108 & 0.115 & 0.146 & 1 & 0.188 \\
SADDS 9 & 0.154 & 0.564 & 0.183 & 0.459 & 0.104 & 0.212 & 0.158 & 0.188 & 1 \\
SADDS 10 & 0.176 & 0.065 & 0.216 & 0.178 & 0.43 & 0.816 & -0.005 & 0.084 & 0.239 \\
SADDS 11 & 0.357 & 0.075 & 0.533 & 0.065 & 0.245 & 0.157 & 0.105 & 0.511 & 0.219 \\
SADDS 12 & 0.104 & 0.1 & 0.196 & 0.124 & 0.718 & 0.606 & 0.096 & 0.213 & 0.265 \\
SADDS 13 & 0.076 & 0.188 & 0.106 & 0.072 & 0.066 & 0.183 & 0.556 & 0.229 & 0.346 \\
SADDS 14 & 0.331 & 0.264 & 0.455 & 0.264 & 0.297 & 0.252 & 0.271 & 0.411 & 0.312 \\
SADDS 15 & 0.081 & 0.413 & 0.178 & 0.511 & 0.29 & 0.201 & 0.106 & 0.28 & 0.489 \\
SADDS 16 & 0.119 & 0.207 & 0.426 & 0.26 & 0.376 & 0.467 & 0.196 & 0.144 & 0.365 \\
SADDS 17 & 0.062 & 0.239 & 0.041 & 0.217 & 0.118 & 0.228 & 0.492 & 0.297 & 0.199 \\
\hline
\end{tabular}


Table 4 - Saudi Arabian diabetes distress scale-17 (SADDS-17) inter-item correlation matrix (continuation).

\begin{tabular}{lcccccccc}
\hline SADDS & SADDS & SADDS & SADDS & SADDS & SADDS & SADDS & SADDS & SADDS \\
Items & $\mathbf{1 0}$ & $\mathbf{1 1}$ & $\mathbf{1 2}$ & $\mathbf{1 3}$ & $\mathbf{1 4}$ & $\mathbf{1 5}$ & $\mathbf{1 6}$ & $\mathbf{1 7}$ \\
\hline SADDS 1 & 0.176 & 0.357 & 0.104 & 0.076 & 0.331 & 0.081 & 0.119 & 0.062 \\
SADDS 2 & 0.065 & 0.075 & 0.1 & 0.188 & 0.264 & 0.413 & 0.207 & 0.239 \\
SADDS 3 & 0.216 & 0.533 & 0.196 & 0.106 & 0.455 & 0.178 & 0.426 & 0.041 \\
SADDS 4 & 0.178 & 0.065 & 0.124 & 0.072 & 0.264 & 0.511 & 0.26 & 0.217 \\
SADDS 5 & 0.43 & 0.245 & 0.718 & 0.066 & 0.297 & 0.29 & 0.376 & 0.118 \\
SADDS 6 & 0.816 & 0.157 & 0.606 & 0.183 & 0.252 & 0.201 & 0.467 & 0.228 \\
SADDS 7 & -0.005 & 0.105 & 0.096 & 0.556 & 0.271 & 0.106 & 0.196 & 0.492 \\
SADDS 8 & 0.084 & 0.511 & 0.213 & 0.229 & 0.411 & 0.28 & 0.144 & 0.297 \\
SADDS 9 & 0.239 & 0.219 & 0.265 & 0.346 & 0.312 & 0.489 & 0.365 & 0.199 \\
SADDS 10 & 1 & 0.264 & 0.582 & 0.066 & 0.285 & 0.114 & 0.492 & 0.06 \\
SADDS 11 & 0.264 & 1 & 0.335 & 0.17 & 0.531 & 0.173 & 0.447 & 0.088 \\
SADDS 12 & 0.582 & 0.335 & 1 & 0.149 & 0.402 & 0.365 & 0.492 & 0.195 \\
SADDS 13 & 0.066 & 0.17 & 0.149 & 1 & 0.403 & 0.221 & 0.172 & 0.627 \\
SADDS 14 & 0.285 & 0.531 & 0.402 & 0.403 & 1 & 0.388 & 0.448 & 0.326 \\
SADDS 15 & 0.114 & 0.173 & 0.365 & 0.221 & 0.388 & 1 & 0.333 & 0.264 \\
SADDS 16 & 0.492 & 0.447 & 0.492 & 0.172 & 0.448 & 0.333 & 1 & 0.263 \\
SADDS 17 & 0.06 & 0.088 & 0.195 & 0.627 & 0.326 & 0.264 & 0.263 & 1 \\
\hline
\end{tabular}

correlation between the DRD and depression symptoms among people with diabetes. ${ }^{24,27,28}$ Diabetes-related distress is a risk factor for the incidence and persistence of depressive symptoms, with a high percentage of patients who had distress were diagnosed as having depression. ${ }^{26,29}$

Our study also revealed a significant positive correlation between DRD and HADS anxiety scores. This relationship has not been adequately addressed previously in the literature. Although this finding could be explained by a previous study that reported that DM patients have a $17-20 \%$ higher risk of developing an anxiety disorder compared with their age-matched controls whom are non-DM participants. ${ }^{30}$ With the known impact of anxiety disorders on those suffering from chronic illnesses, further studies are warranted in order to explain this relationship.

Distressed participants in our current study were found to have a significant negative correlation in the EB domain with participants' educational level. Such a finding is supported by similar correlations reported in the literature associated with more distress. ${ }^{10,26,27}$ These aforementioned studies have reported that low education might lead to poor knowledge on the illness and its complications, which increases the risk of poor dietary habits, poor compliance to medication, and fewer health check-ups. ${ }^{31}$

Significant negative correlations were also observed between the ID domain and the quality of life social relationships domain and environment domain scores (WHOQOL-BREF), which supports the evidence of SADDS-17 validity. Our findings are in line with one study that reported the relationship between chronic diseases and depressive symptoms that have weakened in the presence of higher levels of instrumental social support in an older adult population. ${ }^{32}$ This is an indication that the more social connections and networks a person has, the less they would develop distress, and this might be partly from the additional emotional support that strong social networks can bring, and the less time they spend ruminating on their illness and situation. In addition, the buffering model of social support holds that health-related stressors will have deleterious effects on the health of those with little or no social support, while these effects will be lessened or eliminated for those with stronger support. ${ }^{33}$

Although multiple studies have validated the Arabic version of the DDS-17, our study is strong because it uses a systematic random sampling technique. Also, we have used scales to support the construct validity of the SADDS-17 and its domains. This study was limited by the unavailability of the scree plot, as under the COVID-19 pandemic circumstances we have lost communication with the biostatistician involved in our study, moreover, limited by the necessity of sample exclusion, which was carried out in order to achieve higher accuracy. We recommend further studies in order to explain the relationship between anxiety and diabetes distress. We also encourage that future studies consider a larger sample size to confirm the reported results.

In conclusion, The current study explores a valid, reliable, and consistent Arabic version of the DDS-17 (SADDS-17) in measuring diabetes distress amongst this Saudi Arabic speaking population. This newly 
adapted tool (SADDS-17) will clinically aid in the assessment of diabetes-related distress in our Saudi diabetes population; in addition, it would contribute as a valid Arabic instrument of great benefit in the research field.

\section{References}

1. International Diabetes Federation. Diabetes Atlas. 9th ed. Brussels, Belgium, 2019. [Updated 2021. Accessed 2021 April 13] Available at: https://diabetesatlas.org/en/

2. Alotaibi A, Perry L, Gholizadeh L, Al-Ganmi A. Incidence and prevalence rates of diabetes mellitus in Saudi Arabia: An overview. J Epidemiol Glob Health 2017; 7: 211-218.

3. Aljuaid MO, Almutairi AM, Assiri MA, Almalki DM, Alswat K. Diabetes-related distress assessment among type 2 diabetes patients. Chiefari E, editor. J Diabetes Res 2018; 2018: 7328128.

4. Alzughbi T, Badedi M, Darraj H, Hummadi A, Jaddoh S, Solan Y, et al. Diabetes-related distress and depression in Saudis with type 2 diabetes. Psychol Res Behav Manag 2020; 13: 453-458.

5. Bădescu SV, Tătaru C, Kobylinska L, Georgescu EL, Zahiu DM, Zăgrean AM, et al. The association between diabetes mellitus and depression. J Med Life 2016; 9: 120-125.

6. Fisher L, Skaff MM, Mullan JT, Arean P, Mohr D, Masharani $\mathrm{U}$, et al. Clinical depression versus distress among patients with type 2 diabetes: Not just a question of semantics. Diabetes Care 2007; 30: 542-548.

7. Schmidt CB, van Loon BJP, Vergouwen ACM, Snoek FJ, Honig A. Systematic review and meta-analysis of psychological interventions in people with diabetes and elevated diabetesdistress. Diabet Med 2018; 35: 1157-1172.

8. Fisher L, Mullan JT, Skaff MM, Glasgow RE, Arean P, Hessler D. Predicting diabetes distress in patients with type 2 diabetes: A longitudinal study. Diabet Med 2009; 26: 622-627.

9. Owens-Gary MD, Zhang X, Jawanda S, Bullard KMK, Allweiss $\mathrm{P}$, Smith BD. The importance of addressing depression and diabetes distress in adults with type 2 diabetes. J Gen Intern Med 2019; 34: 320-324.

10. Aljuaid MO, Almutairi AM, Assiri MA, Almalki DM, Alswat K. Diabetes-related distress assessment among type 2 diabetes patients. J Diabetes Res 2018; 2018: 7328128.

11. Darawad MW, Hammad S, Samarkandi O. Evaluating the psychometric properties of the Arabic version of the diabetes distress scale. J Psychosoc Nurs 2017; 55: 43-51.

12. Thanakwang K, Thinganjana W, Konggumnerd R. Psychometric properties of the Thai version of the diabetes distress scale in diabetic seniors. Clin Interv Aging 2014; 9: 1353-1361.

13. Martyn-Nemeth P, Quinn L, Hacker E, Park H, Kujath AS. Diabetes distress may adversely affect the eating styles of women with type 1 diabetes. Acta Diabetol 2014; 51: 683-686.

14. William H. Polonsky, Fisher L, Earles J. Assessing psychosocial distress in diabetes. Diabetes Care 2005; 28: 626-631.

15. Beaton DE, Bombardier C, Guillemin F, Ferraz MB. Guidelines for the process of cross-cultural adaptation of self-report measures. Spine (Phila Pa 1976) 2000; 25: 3186-3191.

16. Fisher L, Glasgow RE, Skaff MM, Polonsky WH. Development of a brief diabetes distress screening instrument. Ann Fam Med 2008; 246-252.
17. Malasi TH, Mirza IA, El-Islam MF. Validation of the hospital anxiety and depression scale in Arab patients. Acta Psychiatr Scand 1991; 84: 323-326.

18. Hayes, MH, Paterson, DG. Experimental developement of the graphics rating method. Physiol Bull 1921; 18: 98-99.

19. Al-Osaimi F, Al-Mulhem A, Al-Shalan H. Psychosocial predictors of patient adherence to disease-modifying therapies for multiple sclerosis. Patient Prefer Adherence 2017; 11: 513-518.

20. Hasanah CI, Naing L, Rahman ARA. World Health Organization quality of life assessment: brief version in Bahasa Malaysia. Med J Malaysia 2003; 58: 79-88.

21. Ohaeri JU, Awadalla AW. The reliability and validity of the short version of the WHO Quality of Life Instrument in an Arab general population. Ann Saudi Med 2009; 29: 98-104.

22. Kaiser HF, Rice J. Little Jiffy, Mark IV. Educ Psychol Meas 1974; 34: 111-117.

23. Ting RZW, Nan H, Yu MWM, Kong APS, Ma RCW, Wong RYM, et al. Diabetes-related distress and physical and psychological health in chinese type 2 diabetic patients. Diabetes Care 2011; 34: 1094-1096.

24. Chew BH, Mukhtar F, Sherina MS, Paimin F, Hassan NH, Jamaludin NK. The reliability and validity of the Malay version 17-item diabetes distress scale. Malays Fam Physician 2015; 10 : 22-35.

25. Graue M, Haugstvedt A, Wentzel-Larsen T, Iversen MM, Karlsen B, Rokne B. Diabetes-related emotional distress in adults: Reliability and validity of the Norwegian versions of the problem areas in diabetes scale (PAID) and the diabetes distress scale (DDS). Int J Nurs Stud 2012; 49: 174-182.

26. Baradaran HR, Mirghorbani S-M, Javanbakht A, Yadollahi Z, Khamseh ME. Diabetes distress and its association with depression in patients with type 2 diabetes in iran. Int J Prev Med 2013; 4: 580-584.

27. Islam MR, Karim MR, Habib SH, Yesmin K. Diabetes distress among type 2 diabetic patients. Int J Med Biomed Res 2013; 2 : 113-124.

28. Fisher L, Skaff MM, Mullan JT. A longitudinal study of affective and anxiety disorders, depressive affect and diabetes distress in adults with type 2 diabetes. Diabet Med 2009; 25: 1096-1101.

29. Ehrmann D, Kulzer B, Haak T, Hermanns N. Longitudinal relationship of diabetes $\bigotimes$ related distress and depressive symptoms: analysing incidence and persistence. Diabet Med 2015; 32: 1264-1271.

30. Tareen RS, Tareen K. Psychosocial aspects of diabetes management: dilemma of diabetes distress. Transl Pediatr 2017; 6: 383.

31. Gahlan D, Rajput R, Gehlawat P, Gupta R. Prevalence and determinants of diabetes distress in patients of diabetes mellitus in a tertiary care centre. Diabetes Metab Syndr 2018; 12: 333-336.

32. Beekman ATF, Penninx B, Deeg DJH, Ormel J, Braam AW, Van Tilburg W. Depression and physical health in later life: results from the Longitudinal Aging Study Amsterdam (LASA). J Affect Disord 1997; 46: 219-231.

33. Cohen S, McKay G. Social support, stress and the buffering hypothesis: A theoretical analysis. Handb Psychol Heal 1984; 4: 253-267. 